\title{
Containment Depressurization Capabilities of Filtered Venting System in 1000 MWe PWR with Large Dry Containment
}

\author{
Sang-Won Lee, Tae-Hyub Hong, Yu-Jung Choi, Mi-Ro Seo, and Hyeong-Taek Kim
}

Korea Hydro and Nuclear Power, Central Research Institute, 70 Gil, Yuseong-Daero 1312, Yuseong-Gu, Daejeon 305-343, Republic of Korea

Correspondence should be addressed to Sang-Won Lee; sangwon@khnp.co.kr

Received 24 February 2014; Revised 26 May 2014; Accepted 29 May 2014; Published 22 June 2014

Academic Editor: Inn Seock Kim

Copyright (C) 2014 Sang-Won Lee et al. This is an open access article distributed under the Creative Commons Attribution License, which permits unrestricted use, distribution, and reproduction in any medium, provided the original work is properly cited.

\begin{abstract}
After the Fukushima Daiichi nuclear power plant accident, the Korean government and nuclear industries performed comprehensive safety inspections on all domestic nuclear power plants against beyond design bases events. As a result, a total of 50 recommendations were defined as safety improvement action items. One of them is installation of a containment filtered venting system (CFVS) or portable backup containment spray system. In this paper, the applicability of CFVS is examined for OPR1000, a 1000 MWe PWR with large dry containment in Korea. Thermohydraulic analysis results show that a filtered discharge flow rate of $15[\mathrm{~kg} / \mathrm{s}]$ at $0.9[\mathrm{MPa}]$ is sufficient to depressurize the containment against representative containment overpressurization scenarios. Radiological release to the environment is reduced to $10^{-3}$ considering the decontamination factor. Also, this cyclic venting strategy reduces noble gas release by $50 \%$ for 7 days. The probability of maintaining the containment integrity in level 2 probabilistic safety assessment (PSA) initiating events is improved twofold, from $43 \%$ to $87 \%$. So, the CFVS can further improve the containment integrity in severe accident conditions.
\end{abstract}

\section{Introduction}

After the Fukushima Daiichi nuclear power plant accident [1], the Korean government and industry performed comprehensive special safety inspections on all domestic nuclear power plants against beyond design bases external events. The major concerns of the inspection were protection against extreme natural hazards, prevention of severe accidents, mitigation of severe accidents, emergency preparedness, and design of structures and equipment against earthquakes and coastal flooding. As a result, a total of 50 recommendations were defined as safety improvement action items. These were classified into 5 categories, as shown in Table 1, and should be implemented.

One of the major action items in mitigation of severe accidents is to maintain containment integrity against overpressurization scenarios. Containment may lose its functional capability as last barrier of radioactive material release to the environment due to overpressurization as a consequence of long-term steam and noncondensable gas generation by molten core concrete interaction (MCCI) [2].
The possible means to mitigate overpressurization are internal decay heat removal, external cooling of the containment surface, and containment venting [3]. Internal heat removal is the most obvious concept that can be used to prevent steam generation inside the containment. However, in cases of severe accidents caused by station blackout (SBO) or loss of recirculation, independent overpressurization protection facilities, such as portable equipment or severe accident grade spray, should be designed to mitigate accidents. Also, external cooling of the containment surface requires steel containment for effective heat transfer to the atmosphere.

The basic idea of a filtered venting system is to open a controlled flow path to the external environment to relieve the steam and noncondensable gases that are generated inside the containment. By doing this, it is possible to delay or prevent structural failure of the containment. Also it provides additional time to mitigate the accident and reduces the offsite consequences compared to those produced by containment failure. Typically, the decontamination efficiency of an external filter against aerosol is required to be $99.9 \%$ in order 
TABLE 1: Safety improvement action items in Korea after Fukushima accidents.

\begin{tabular}{|c|c|}
\hline Categories & Major action item \\
\hline $\begin{array}{l}\text { (1) Design of structures and equipment } \\
\text { against earthquakes }\end{array}$ & $\begin{array}{l}\text { (i) Installing an automatic seismic trip system } \\
\text { (ii) Improving seismic capability of the safe shutdown systems and MCR } \\
\text { (iii) Reassessment of maximum potential earthquakes for nuclear plant sites }\end{array}$ \\
\hline $\begin{array}{l}\text { (2) Design of structures and equipment } \\
\text { against coastal flooding }\end{array}$ & $\begin{array}{l}\text { (i) Extension of the height of sea wall } \\
\text { (ii) Installation of waterproof gates and discharge pump } \\
\text { (iii) Investigation of the design basis sea water level of nuclear plant sites }\end{array}$ \\
\hline $\begin{array}{l}\text { (3) Integrity of electric power, cooling, } \\
\text { and fire protection system upon } \\
\text { inundation }\end{array}$ & $\begin{array}{l}\text { (i) Securing availability of portable power generator vehicles and batteries } \\
\text { (ii) Upgrading design basis of alternative AC diesel generators } \\
\text { (iii) Ensuring countermeasure against loss of spent fuel pool cooling function } \\
\text { (iv) Improving fire protection facilities and fire protection plan }\end{array}$ \\
\hline $\begin{array}{l}\text { (4) Countermeasures against severe } \\
\text { accidents }\end{array}$ & $\begin{array}{l}\text { (i) Installation of passive hydrogen removal equipment } \\
\text { (ii) Installation of filtered vent system or backup spray system } \\
\text { (iii) Revision of severe accident management guidelines to enhance effectiveness } \\
\text { (iv) Installation of reactor injection flow path from external cooling source }\end{array}$ \\
\hline (5) Emergency response & $\begin{array}{l}\text { (i) Amending emergency plans to address concurrent events at multiple units } \\
\text { (ii) Development of extensive damage mitigation guidelines }\end{array}$ \\
\hline
\end{tabular}

to prevent long-term ground contamination and 99\% for elemental iodine to limit thyroid doses and the need for shortterm evacuation [4].

Different kinds of filtered venting design were investigated in the 1980s, such as sand/gravel filters, scrubbing through a water pool, scrubbing through a bed of ice in the PWR ice condenser containment, scrubbing through a venturi scrubber in a water pool and a metallic mesh filter outside the containment, and dry filters [5]. Also, different containment filtered venting strategies were proposed [6]. After the Chernobyl accident, several European countries (France, Sweden, and Germany) installed containment filtered venting systems (CFVS). In Switzerland, all nuclear power plants had installed filtered venting systems and theirs design characteristics had been described [4]. However, the negative impacts of filtered venting systems, such as containment subatmospheric pressure, hydrogen buildup in the filtered venting system due to condensation in the subcooled water pool, and unnecessary release of radioactive material due to inadvertent opening, had been studied in the US $[5,7,8]$. Also, estimation of the risk reduction factor of filtered venting was found to vary from 2 to 100 based on plant design and assumptions but still has large uncertainties [9-11].

After the Fukushima Daiichi nuclear power plant accident, many countries reexamined the applicability of filtered venting as a mitigation measure for containment integrity [12, 13]. In Korea, four pressurized heavy water reactors (PHWR) will install the CFVS because their containment designs are vulnerable compared to that of a conventional PWR. In this paper, the depressurization capability and the effects on safety improvement of CFVS will be examined for a $1000 \mathrm{MWe}$ PWR with large dry containment.

\section{Severe Accident Analysis}

To assess the severe accident mitigation effect of CFVS, analyses of containment overpressurization scenarios are performed using the MAAP4 computer code [14]. The MAAP

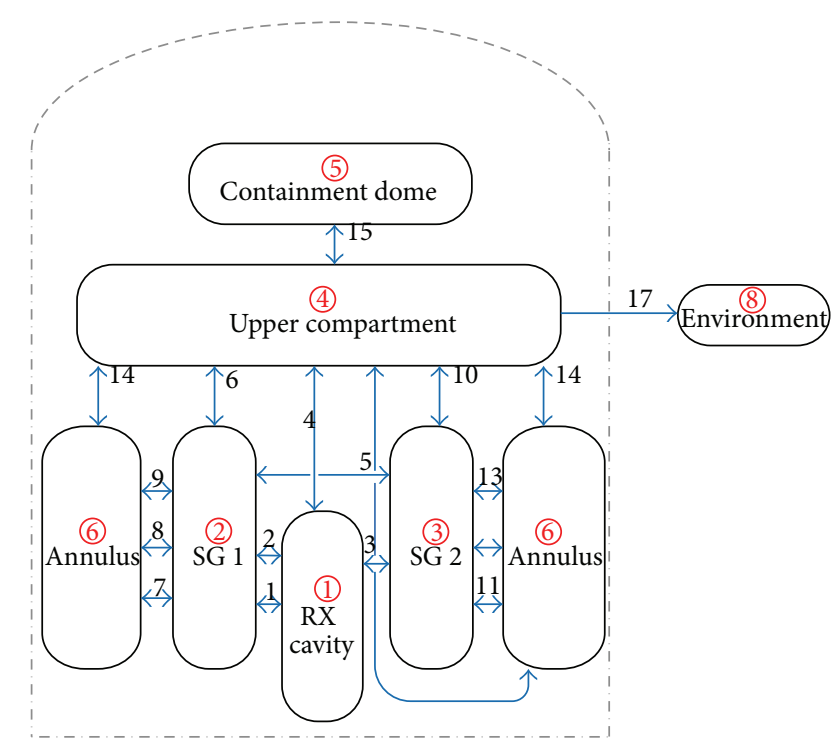

FIGURE 1: Containment noding diagram.

code can analyze severe accidents following loss of coolant accidents (LOCAs), SBOs, and various general transients. Developed for the Electric Power Research Institute (EPRI) by Fauske et al., MAAP4.0.4 is used here. MAAP4 has a simplified thermohydraulic model and solves first-order differential equations for conservation of mass and energy. However, it has a reasonable prediction capability comparable to those of MELCOR and SCDAP [15]. Also, recently, technical justification of the MAAP4 code for post-Fukushima applications has been performed [16].

The reference plant is OPR1000, a 1000 MWe large dry PWR in Korea. A containment noding diagram for OPR1000 is shown in Figure 1. In OPR1000, ultimate containment failure pressure with $5 \%$ probability $95 \%$ confidence level is $1.01 \mathrm{MPa}$ and it is used in hardened venting without an external filter in severe accident management guidelines [17]. 
TABLE 2: Initial and boundary conditions.

\begin{tabular}{lc}
\hline Parameter & Value \\
\hline Rx power & $2815\left[\mathrm{MW}_{\text {th }}\right]$ \\
CTMT net free volume & $7.73 \times 10^{4}\left[\mathrm{~m}^{3}\right]$ \\
CTMT design pressure & $0.5[\mathrm{MPa}]$ \\
CTMT ultimate pressure & $1.01[\mathrm{MPa}]$ \\
& $0.9 / 0.6[\mathrm{MPa}]$ \\
CFVS opening/closing set-point & $0.5 / 0.2[\mathrm{MPa}]$ \\
& $17 \mathrm{~kg} / \mathrm{s} @ 0.9 \mathrm{MPa}$ \\
CFVS flow rate & $10 \mathrm{~kg} / \mathrm{s} @ 0.5 \mathrm{MPa}$ \\
\hline
\end{tabular}

CFVS is modelled as a junction connecting the containment upper compartment to the environment. Venting area is assumed to be $230 \mathrm{~mm}$ (9 inch) in diameter and flow resistance through the CFVS is considered. To activate the CFVS, the containment isolation valves should be opened either by the operator (active means) or by the rupture disc (passive means) when the set-point is reached. A decontamination factor of 1,000 for aerosol is assumed in this calculation. Representative containment venting strategies are divided into early venting (venting before core heatup) and late venting (venting beyond containment design pressure). The disadvantage of the early venting strategy is that depressurization occurs at a time when the fission product level in the containment is high and aerosol deposition begins. So, the aerosol loading of the vent system is high in that period. However, late venting has some potential benefits in preventing a large amount of uncontrolled release of radioactive materials to the environment and no negative influence on the hydrogen explosion [6].

The containment pressure behavior is analyzed for three different cases: without venting, with cyclic venting at severe accident pressure of $0.9 \mathrm{MPa} / 0.6 \mathrm{MPa}$ (CFVS-9 case), and with cyclic venting at containment design pressure of $0.5 \mathrm{MPa} / 0.2 \mathrm{MPa}$ (CFVS- 5 case). Without a closing set-point, the containment pressure reaches $0.1 \mathrm{MPa}$. Then, pressure becomes unstable and a small amount of steam condensation leads to subatmospheric pressure, especially in the ice condenser containment [3]. So, the cyclic venting strategy is assumed to prevent subatmospheric pressure concerns.

Initial and boundary conditions are summarized in Table 2. Major analysis scenarios are extended SBO and LBLOCA. These scenarios are chosen based on representative PSA initiating events that are expected to envelope the containment overpressurization accident [18].

2.1. Effect on $S B O$ Scenarios. $\mathrm{SBO}$ is a representative high pressure scenario. In a SBO, molten debris and coolant discharged into containment are in a superheated condition and lead to rapid containment pressurization. The initiating event is a SBO concurrent with failure of the alternative AC. At $9.0 \mathrm{sec}$, the SG safety valve opens due to the primary to secondary heat transfer. The turbine driven auxiliary feedwater system is assumed to fail. So, the SG inventory is depleted at $50 \mathrm{~min}$. Also, emergency core cooling system and containment spray system are not available. So the RCS

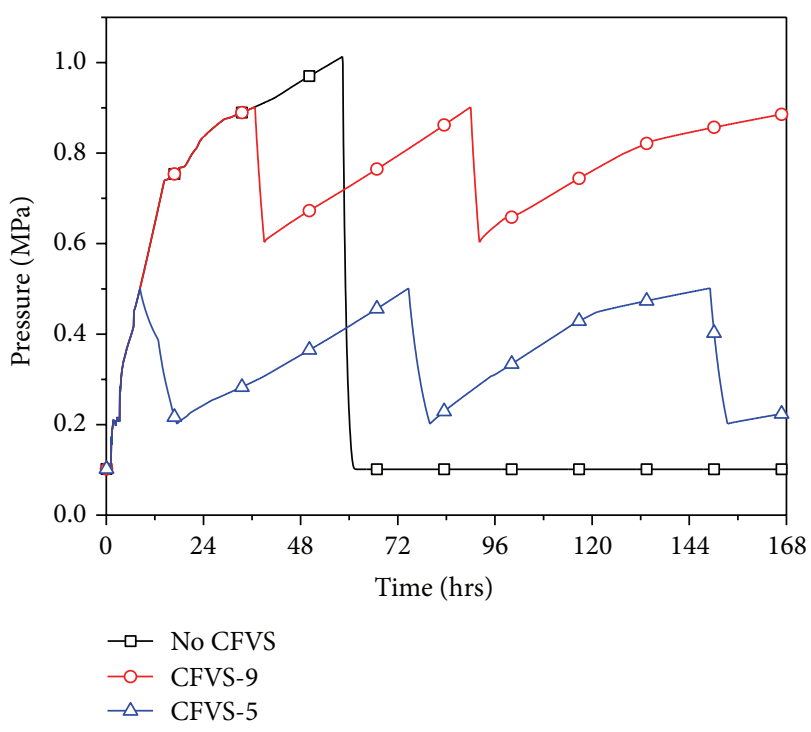

FIGURE 2: Containment pressure history in extended SBO.

inventory is continuously discharged into the containment via the pressurizer safety valve and the core starts to uncover at $1.6 \mathrm{hrs}$. Core exit temperature reaches severe accident management guideline entry condition of $922 \mathrm{~K}$ at $2.0 \mathrm{hrs}$. However, there are no mitigation measures available. Finally the reactor vessel fails at $3.3 \mathrm{hrs}$. Because high pressure is maintained before the RCS fail, a large amount of superheated steam and hydrogen are discharged into the containment. Also, interaction between the molten core material and the cavity water that is discharged from accumulator leads to a large amount of steam generation in the cavity. So, the containment pressure rapidly increases, so-called steam spike. After the cavity water is depleted, hydrogen and noncondensable gas are generated by molten core concrete interaction in the base-mat. After $58.4 \mathrm{hrs,} \mathrm{the} \mathrm{containment} \mathrm{pressure}$ reaches its ultimate pressure and leads to containment failure. Table 3 summarizes the sequence of events.

However, the CFVS-9 case shows that the CFVS starts to operate at $36.8 \mathrm{hrs}$ as shown in Figure 2. Then, the containment pressure rapidly decreases to the closing set-point of $0.6 \mathrm{MPa}$ within $2.2 \mathrm{hrs}$. On the other hand, the CFVS- 5 case shows that the CFVS starts to operate at $8.4 \mathrm{hrs}$ and maintains for $9.1 \mathrm{hrs}$ due to the relatively large decay heat level and its limited venting flow-rate, which is due to small pressure difference, as shown in Figure 3.

Fractional releases of radioactive material without CFVS and that for the CFVS case are compared in Figures 4 and 5. Most of the radioactive material releases to the environment are reduced substantially due to the effect of the decontamination factor of 1,000 in the CFVS case. In addition, the cyclic venting strategy reduces the noble gas release to $\sim 50 \%$ in the CFVS- 9 case, as shown in Figure 6. With respect to the opening set-point, the CFVS-9 case is beneficial for radioactive releases to the environment because CFVS operating timing is delayed and operation duration is shorter compared to that of the CFVS-5 case. Also, aerosol loading is decreased due to the fact that the deposition inside 
TABLE 3: Extended SBO sequence of event.

\begin{tabular}{|c|c|c|c|}
\hline Event summary & No CFVS & CFVS@0.9 MPa & CFVS@0.5 MPa \\
\hline $\begin{array}{l}\text { SBO occurs } \\
\text { Rx Scram } \\
\text { No ECCS/spray/aux feed avai }\end{array}$ & $0.0 \mathrm{sec}$ & & \\
\hline 2nd safetyv cycling & $9.0 \mathrm{sec}$ & & \\
\hline SG dryout & $50 \mathrm{~min}$ & & \\
\hline Primary safety valve cycling & $50 \mathrm{~min}$ & & \\
\hline Core uncover & $1.6 \mathrm{Hr}$ & & \\
\hline CET > $1200 \mathrm{~F}$ (SAMG entry) & $2.0 \mathrm{Hr}$ & & \\
\hline Vessel failure & $3.3 \mathrm{Hr}$ & & \\
\hline CFVS opening/closing & - & $\begin{array}{l}\text { 36.8 Hrs/39.0 Hrs } \\
90.1 \mathrm{Hrs} / 92.2 \mathrm{Hrs}\end{array}$ & $\begin{array}{c}\text { 8.4 Hrs/17.5 Hrs } \\
74.6 \mathrm{Hrs} / 80.0 \mathrm{Hrs} \\
149.2 \mathrm{Hrs} / 153.5 \mathrm{Hrs}\end{array}$ \\
\hline Containment failure & $58.4 \mathrm{Hrs}$ & No fail & No fail \\
\hline Calc. end & $168 \mathrm{Hr}$ & & \\
\hline
\end{tabular}

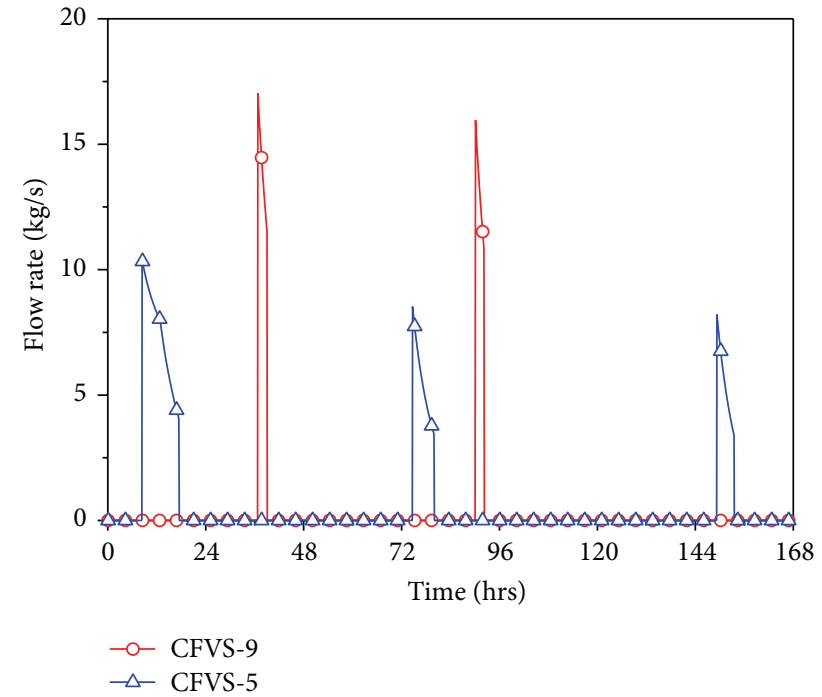

FIGURE 3: CFVS discharge flow rate in extended SBO.

the containment occurs during delayed venting, as shown in Figure 7.

2.2. Effect on LBLOCA Scenarios. LBLOCA is the representative low pressure scenario. The initiating event is a cold leg double-ended guillotine break at $0.0 \mathrm{sec}$. After the blowdown phase, RCS depressurization leads to accumulator injection for initial core quenching. Due to the large amount of accumulator water, some of the spilled water is collected into the reactor cavity. The containment pressure decreases after its initial peak during the blow-down phase due to the passive heat sink in the containment. However, all of emergency core cooling systems fail to deliver when the injection signal occurs. Eventually, molten corium relocation to the lower head occurs at 1.4 hrs. During this time period, the containment pressure continuously increases due to the break steam flow rate to the containment. Finally, RCS fails at $2.4 \mathrm{hrs}$. Interaction between the molten core material and

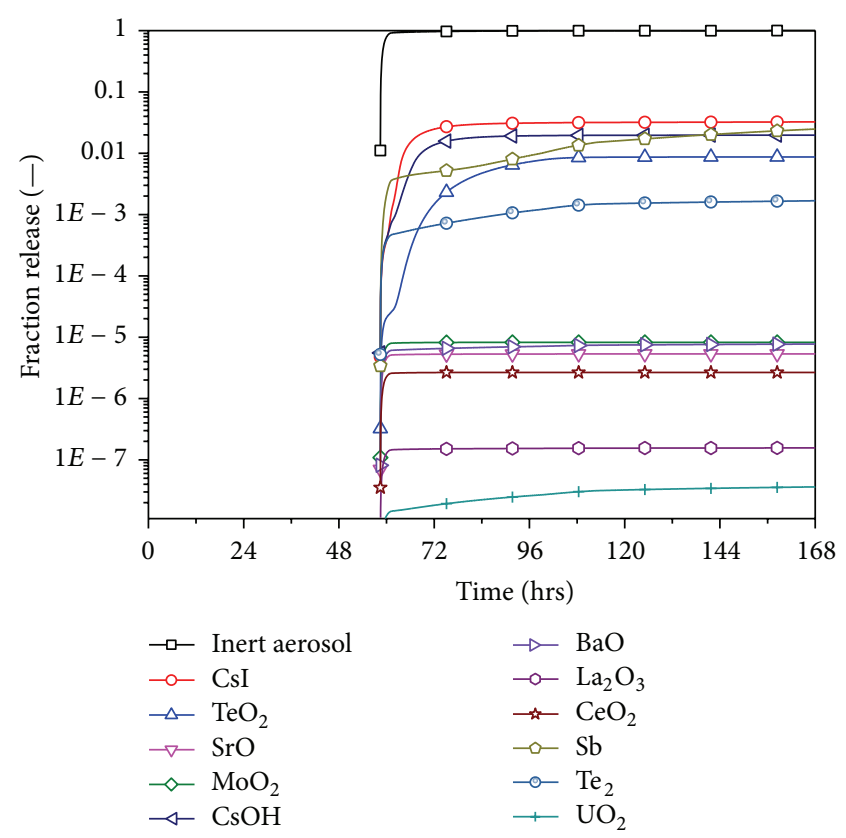

FIGURE 4: Fractional release of radioactive material without CFVS in extended SBO.

the cavity water leads to a large amount of steam generation in the cavity. So, the containment pressure reincreases. Also, hydrogen and noncondensable gas are steadily generated by the molten core concrete interaction in the base-mat. The containment pressure reaches its ultimate pressure at $53.8 \mathrm{hrs}$. Table 4 summarizes the sequence of events.

The CFVS-9 case shows that the CFVS starts to operate at 28.0 hrs as shown in Figure 8. Then, the containment pressure rapidly decreases to the closing set-point of $0.6 \mathrm{MPa}$ within $2.3 \mathrm{hrs}$. On the other hand, the CFVS-5 case shows that the CFVS starts to operate at $4.4 \mathrm{hrs}$ and maintains for $9.6 \mathrm{hrs}$. This activation time is just 2 hrs after the RCS fails. So, a relatively large amount of noble gas and CsI are released to the environment, as shown in Figures 9 and 10. 
TABLE 4: LBLOCA sequence of event.

\begin{tabular}{|c|c|c|c|}
\hline Event summary & No CFVS & CFVS@0.9 MPa & CFVS@0.5 MPa \\
\hline $\begin{array}{l}\text { Cold leg LBLOCA occurs } \\
\text { Rx Scram } \\
\text { No CTMT spray/aux feed }\end{array}$ & $0.0 \mathrm{sec}$ & & \\
\hline PZR empty & $7.0 \mathrm{sec}$ & & \\
\hline Core uncovery & $8.0 \mathrm{sec}$ & & \\
\hline Accumulator empty & $41.0 \mathrm{sec}$ & & \\
\hline Relocation to lower head & $1.4 \mathrm{Hrs}$ & & \\
\hline Vessel failure & $2.4 \mathrm{Hrs}$ & & \\
\hline CFVS opening/closing & & $\begin{array}{c}28 \mathrm{Hrs} / 30.3 \mathrm{Hrs} \\
\text { 88.1 Hrs/90.2 Hrs } \\
151.8 \mathrm{Hrs} / 153.8 \mathrm{Hrs}\end{array}$ & $\begin{array}{c}\text { 4.4 Hrs/14.0 Hrs } \\
\text { 68.0 Hrs/73.3 Hrs } \\
\text { 137.5 Hrs/141.9 Hrs }\end{array}$ \\
\hline Containment failure & $53.8 \mathrm{Hrs}$ & No fail & No fail \\
\hline Calc. end & $168 \mathrm{Hr}$ & & \\
\hline
\end{tabular}

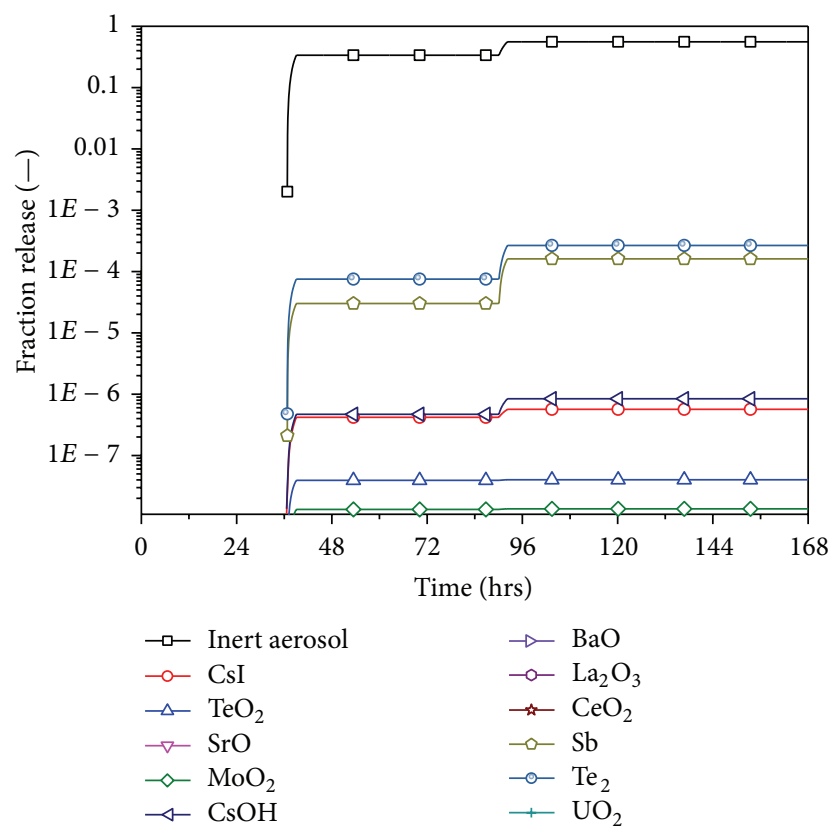

FIGURE 5: Fractional release of radioactive material with CFVS-9 case in extended SBO.

2.3. Analysis Results. Analysis results show that the OPR 1000 could maintain its integrity against severe accident overpressurization scenarios for 2 3 days due to the design characteristic of sufficient free volume in the large dry containment. However, if operator recovery action for containment depressurization or cooling function using existing active system (i.e., containment spray system or fan cooler) is not successful within this time, the containment may lose its functional capability as the last barrier against fission product release into the environment.

When CFVS is in place, containment pressure reaches the CFVS set-point approximately $1 \sim 2$ days after the initial event. Then, a filtered discharge flow rate of $17[\mathrm{~kg} / \mathrm{s}]$ at $0.9 \mathrm{MPa}$ is sufficient to depressurize the containment in most of the late containment failure scenarios. Also 2 3 times of operation

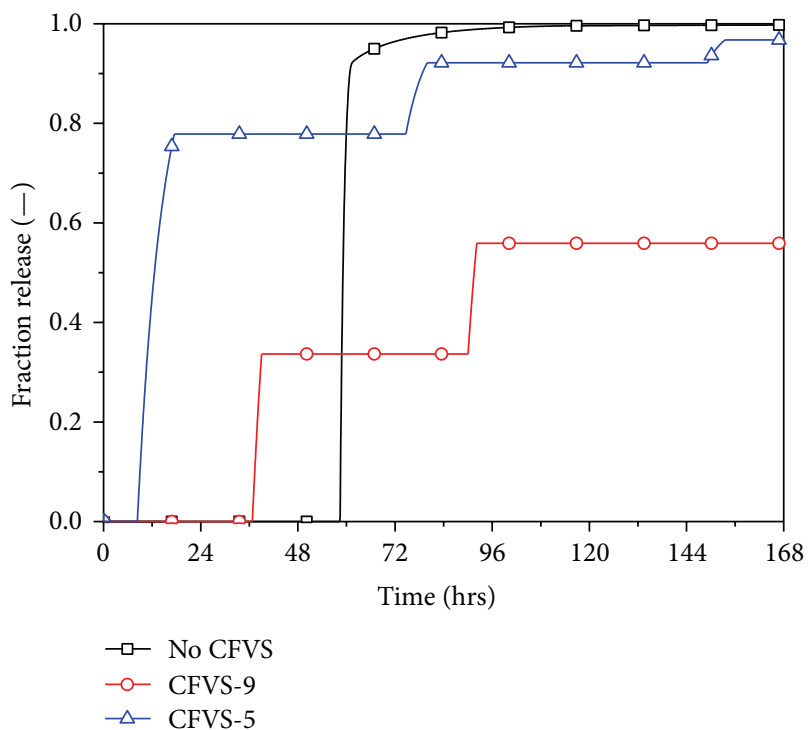

FIGURE 6: Comparison of fractional release of noble gas in extended SBO.

in a 7-day period are sufficient to control the containment pressure. Radiological release to the environment is reduced to $10^{-3}$ considering the decontamination factor. In addition, the cyclic venting strategy can reduce the noble gas release by $50 \%$ for 7 days. As for containment penetration, OPR1000 satisfies regulatory requirement 10CFR50.34(f) which requires $3 \mathrm{ft}$ diameter containment penetration for venting provision. And a $17[\mathrm{~kg} / \mathrm{s}]$ flow rate is roughly equivalent to a penetration diameter of 9 inches.

\section{PSA Assessment}

To assess the safety improvement effects on PSA, the current OPR1000 level 2 PSA model is examined [18]. In level 2 PSA, the general containment failure modes can be divided into six categories [19]. 


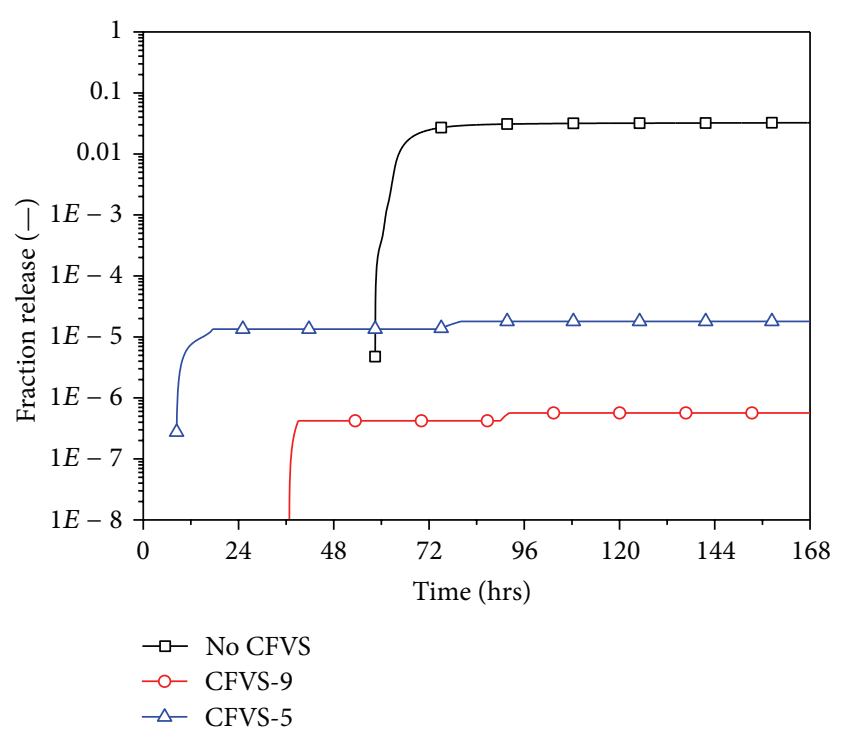

Figure 7: Comparison of fractional release of CsI in extended SBO.

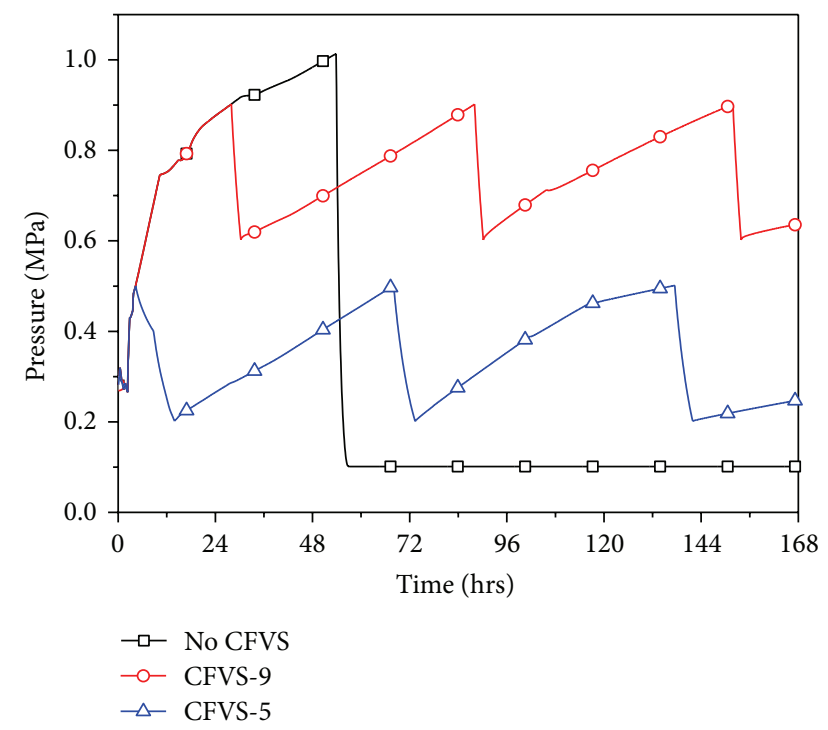

FIgURE 8: Containment pressure history in LBLOCA.

(i) No containment failure (NO CF): core damage occurs in the reactor vessel, but the molten corium does not penetrate the reactor vessel lower head. And containment integrity is maintained.

(ii) Early containment failure (ECF): containment failure occurs at a relatively early stage of the event. Major phenomena are violent hydrogen explosion, direct containment heating, steam explosion, and so forth.

(iii) Late containment failure (LCF): containment failure occurs 2 3 days after the reactor vessel failure by continuous overpressurization due to molten core concrete interaction and steam generation.

(iv) Base-mat melt-through (BMT): the molten corium interacts with the concrete floor of the reactor building and melts through the containment floor.

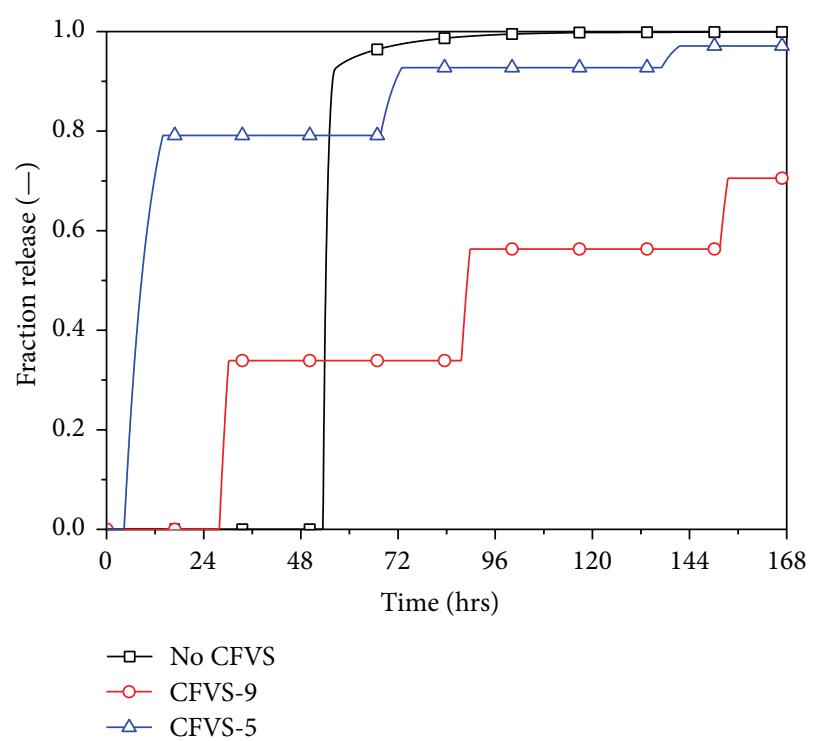

FIGURE 9: Comparison of fractional release of noble gas in LBLOCA.

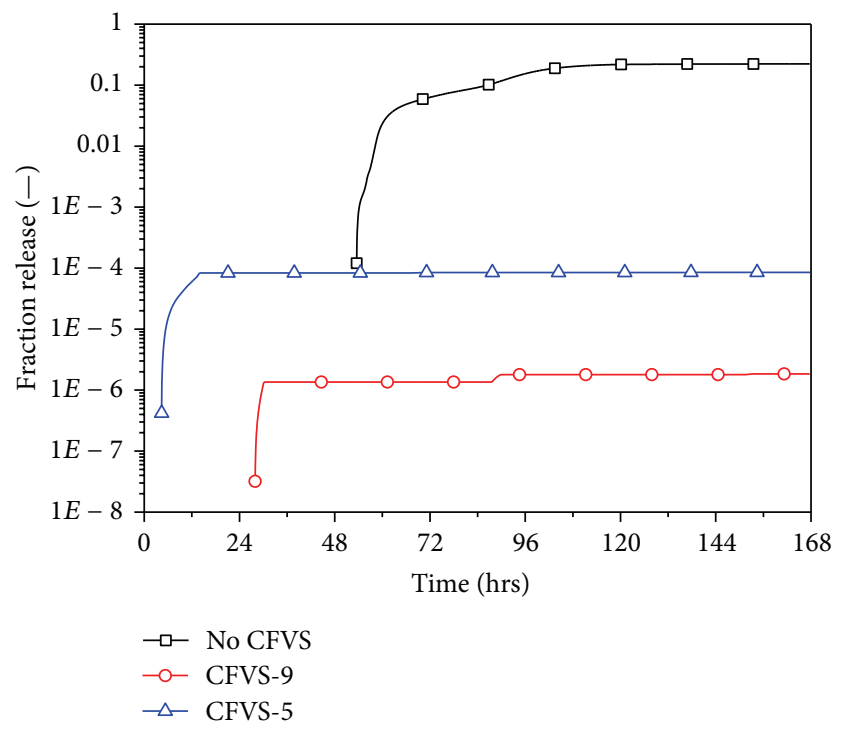

Figure 10: Comparison of fractional release of CsI in LBLOCA.

(v) Isolation failure (NOT ISO): Although the containment integrity is maintained, the containment pressure boundary is damaged by containment isolation failure and radioactive material is released to the outside containment.

(vi) Containment bypass (BYPASS): fission products generated in the core are released outside the containment directly through containment penetration. Steam generator tube rupture (SGTR) accident and interfacing system LOCA (ISLOCA) are included in this category.

3.1. Effectiveness of CFVS against Level 2 PSA Internal Event. To assess the overall beneficial impact of CFVS, several 
TABLE 5: Containment event tree of OPR1000.

\begin{tabular}{|c|c|c|c|c|}
\hline CET Heading & Definition & Subbranch & $\begin{array}{l}\text { Effect on } \\
\text { CFVS }\end{array}$ & Remark \\
\hline RCSFAIL & RCS fail before RV fail & $\begin{array}{c}\text { No fail } \\
\text { HL Break } \\
\text { SGTR }\end{array}$ & $\begin{array}{l}- \\
- \\
\text { No }\end{array}$ & Bypass \\
\hline MELTSTOP & $\begin{array}{l}\text { Core melt progression } \\
\text { Stopped before RV fail }\end{array}$ & $\begin{array}{l}\text { Melt stop } \\
\text { RV rupture } \\
\text { CFBRB }\end{array}$ & $\begin{array}{c}- \\
\text { Yes }\end{array}$ & \\
\hline ALPHA & $\begin{array}{l}\text { ALPHA mode containment } \\
\text { failure }\end{array}$ & $\begin{array}{c}\text { No fail } \\
\text { Fail } \\
\end{array}$ & $\overline{\mathrm{No}}$ & Early CTMT failure \\
\hline CR-EJECT & $\begin{array}{l}\text { Amount of corium ejected } \\
\text { out of cavity }\end{array}$ & High, medium, low & - & \\
\hline CF-EARLY & Early containment failure & $\begin{array}{c}\text { No fail } \\
\text { Leak/Rupture }\end{array}$ & $\overline{\text { No }}$ & Early CTMT failure \\
\hline CS-LATE & Recirculation spray failure & No fail, fail & - & \\
\hline EXVCOOL & Debris cooled ex-vessel & No cooled, cooled & - & \\
\hline CF-LATE & Late containment failure & $\begin{array}{c}\text { No fail } \\
\text { Leak/rupture }\end{array}$ & $\overline{-}$ & \\
\hline
\end{tabular}

factors should be considered such as system unavailability due to component failure and inadvertent opening of CFVS $[9,10]$. These failure probabilities depend on system design configuration. In this study, these failures are not considered because CFVS is simple and works passively. So, level 2 PSA internal events are examined with respect to conditional containment failure probability (CCFP) and containment failure frequency. The containment performance analysis estimates the failure probability of the containment for all of the core damage sequences using the containment event tree (CET), shown in Figure 11. To quantify CET, the decomposition of the event trees is performed for each of the CET headings in OPR1000. There are 9 representative CET headings and 95 sequences. The definition and subbranch of each CET heading that is related to the CFVS installation are summarized in Table 5. Qualitative assessment results show that 21 out of a total of 95 existing sequences are selected as scenarios that can be improved by installation of CFVS, as shown in Table 6. The total containment failure frequency that can be prevented by the installation of the CFVS is calculated as $7.295 E-07 / y r$. Current total containment failure frequency for the OPR1000 is $1.88 E-06 / \mathrm{yr}$. So, the safety improvement effect of the CFVS is determined to be a $39 \%$ reduction in the containment failure frequency. Also, CCFP is reduced from 0.337 to 0.2 .

\subsection{Effectiveness of CFVS against Level 2 PSA External Event.} In order to evaluate the overall effect of safety improvement by CFVS installation, external event PSA results, including those for earthquake and fire, are considered. So, a rough estimation of the overall safety improvement effect was determined based on each containment failure mode. The major assumption for external event scenarios is that late containment failure and containment failure before reactor breach (CFBRB) can be prevented by CFVS because the major factors of these failure modes are the loss of cooling and/or depressurization of the containment, such as containment spray or containment fan cooler [9]. Also, containment overpressurization occurs mostly $2 \sim 3$ days after an initiating event. So, the operator has sufficient time to perform the proper action based on SAMG. Table 7 briefly shows the assessment results. As can be seen in the table, probability of maintaining containment integrity is improved from $43 \%$ to $87 \%$.

\section{Conclusions}

After the Fukushima Daiichi nuclear power plant accident, one of the safety improvement action items in Korea is the installation of containment filtered venting systems. So, the applicability of CFVS is examined for OPR1000, a $1000 \mathrm{MWe}$ PWR with large dry containment.

The following are the conclusions.

(i) OPR1000 could maintain its integrity against severe accident overpressurization scenarios for $2 \sim 3$ days due to the sufficient free volume in large dry containment.

(ii) Filtered discharge flow rate of $15[\mathrm{~kg} / \mathrm{s}]$ at $0.9[\mathrm{MPa}]$ is sufficient to depressurize the containment during the overpressurization scenarios.

(iii) Radiological release to the environment is reduced to $10^{-3}$ using current filtered venting technology.

(iv) Late venting is beneficial for aerosol loading and compact design because operating timing is delayed and operation duration is shorter.

(v) Cyclic venting strategy reduces the possibility of noble gas release to the environment.

(vi) Probability of maintaining containment integrity in level 2 probabilistic safety assessment (PSA) initiating events is improved substantially. 


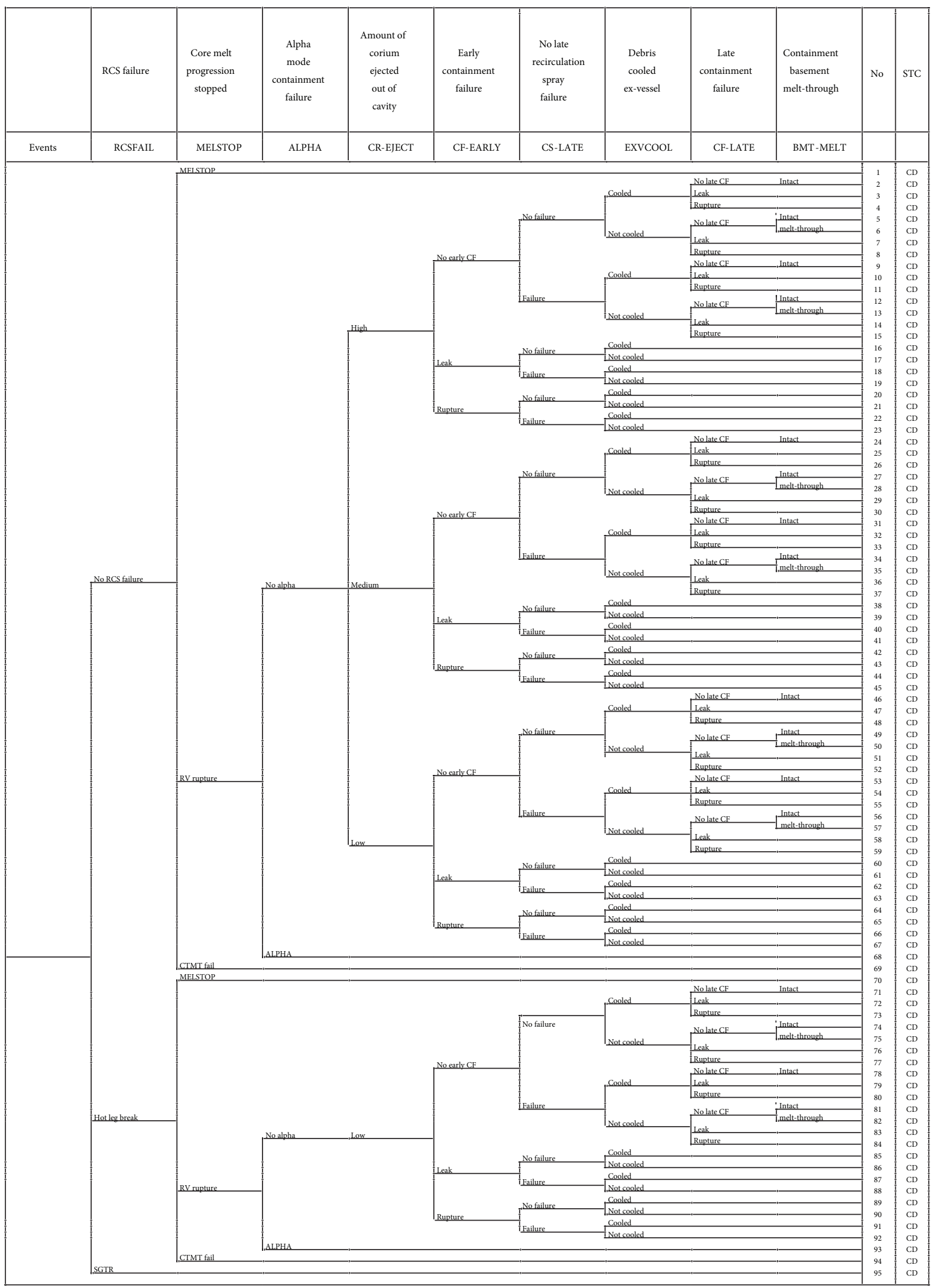

FIGURE 11: Representative containment event tree. 
TABLE 6: Level 2 PSA internal event affected by CFVS.

\begin{tabular}{|c|c|c|c|c|c|c|c|c|}
\hline RCSFAIL & MELTSTOP & ALPHA & CR-EJECT & CF-EARLY & CS-LATE & EXVCOOL & CF-LATE & Seq \\
\hline No RCS failure & RV rupture & No alpha & High & No early CF & Failure & Cooled & Leak & 10 \\
\hline No RCS failure & RV rupture & No alpha & High & No early CF & Failure & Cooled & Rupture & 11 \\
\hline No RCS failure & RV rupture & No alpha & High & No early CF & Failure & Not cooled & Leak & 14 \\
\hline No RCS failure & RV rupture & No alpha & High & No early CF & Failure & Not cooled & Rupture & 15 \\
\hline No RCS failure & RV rupture & No alpha & Medium & No early CF & Failure & Cooled & Leak & 32 \\
\hline No RCS failure & RV rupture & No alpha & Medium & No early CF & Failure & Cooled & Rupture & 33 \\
\hline No RCS failure & RV rupture & No alpha & Medium & No early CF & Failure & Not cooled & Leak & 36 \\
\hline No RCS failure & RV rupture & No alpha & Medium & No early CF & Failure & Not cooled & Rupture & 37 \\
\hline No RCS failure & RV rupture & No alpha & Low & No early CF & No failure & Not cooled & Rupture & 52 \\
\hline No RCS failure & RV rupture & No alpha & Low & No early CF & Failure & Cooled & Leak & 54 \\
\hline No RCS failure & RV rupture & No alpha & Low & No early CF & Failure & Cooled & Rupture & 55 \\
\hline No RCS failure & RV rupture & No alpha & Low & No early CF & Failure & Not cooled & Leak & 58 \\
\hline No RCS failure & RV rupture & No alpha & Low & No early CF & Failure & Not cooled & Rupture & 59 \\
\hline No RCS failure & CTMNT fail & - & - & - & - & - & - & 60 \\
\hline Hot leg break & RV rupture & No alpha & Low & No early CF & No failure & Not cooled & Leak & 76 \\
\hline Hot leg break & RV rupture & No alpha & Low & No early CF & No failure & Not cooled & Rupture & 77 \\
\hline Hot leg break & RV rupture & No alpha & Low & No early CF & Failure & Cooled & Leak & 79 \\
\hline Hot leg break & RV rupture & No alpha & Low & No early CF & Failure & Cooled & Rupture & 80 \\
\hline Hot leg break & RV rupture & No alpha & Low & No early CF & Failure & Not cooled & Leak & 83 \\
\hline Hot leg break & RV rupture & No alpha & Low & No early CF & Failure & Not cooled & Rupture & 84 \\
\hline Hot leg break & CTMNT fail & - & - & - & - & - & - & 94 \\
\hline
\end{tabular}

TABLE 7: Overall safety improvement effect by the installation of the CFVS.

\begin{tabular}{|c|c|c|c|c|c|}
\hline \multirow{2}{*}{ Category } & \multirow{2}{*}{ Internal event } & \multicolumn{2}{|c|}{ External event } & \multirow{2}{*}{ Current design } & \multirow{2}{*}{ w/CFVS } \\
\hline & & Fire & Seismic & & \\
\hline No containment failure & 66.3 & 40.0 & 39.3 & 43.1 & 87.3 \\
\hline Early containment failure & 0.5 & 1.0 & 1.0 & 0.9 & 0.9 \\
\hline Late containment failure & 12.5 & 46.1 & 48.2 & 43.1 & 0.0 \\
\hline Base-mat melt through & 3.8 & 4.8 & 4.5 & 4.4 & 4.4 \\
\hline CFBRB & 5.9 & 0.2 & 0.3 & 1.1 & 0.0 \\
\hline Isolation failure & 1.5 & 6.9 & 5.4 & 4.9 & 4.9 \\
\hline Containment bypass & 9.5 & 1.1 & 1.2 & 2.4 & 2.4 \\
\hline Sum & 100 & 100 & 100 & 100 & 100 \\
\hline
\end{tabular}

(vii) Overall, CFVS can further improve the containment integrity in severe accident conditions.

\section{Conflict of Interests}

The authors declare that there is no conflict of interests regarding the publication of this paper.

\section{Acknowledgments}

This work was supported by the Nuclear Research and Development of the Korea Institute of Energy Technology and Planning (KETEP) Grant funded by the Korean Government, Ministry of Trade, Industry, and Energy (20111510100020).

\section{References}

[1] TEPCO, "Overview of the Earthquake \& Tsunami and Nuclear Accident : The Great East Japan Earthquake and Current Status of Nuclear Power Stations," 2011.

[2] B. De Boeck, "Prevention and mitigation measures to ensure containment integrity," Nuclear Engineering and Design, vol. 209, no. 1-3, pp. 147-154, 2001.

[3] H. Tuomisto, "Filtered venting considerations of an ice condenser containment," Nuclear Engineering and Design, vol. 117, no. 1, pp. 25-31, 1989.

[4] H. Rust, C. Tännler, W. Heintz, D. Haschke, M. Nuala, and R. Jakab, "Pressure release of containments during severe accidents in Switzerland," Nuclear Engineering and Design, vol. 157, no. 3, pp. 337-352, 1995. 
[5] R. O. Schlueter and R. P. Schmitz, "Filtered vented containments," Nuclear Engineering and Design, vol. 120, no. 1, pp. 93103, 1990.

[6] K. Bracht and M. Tiltmann, "Analysis of strategies for containment venting in case of severe accidents," Nuclear Engineering and Design, vol. 104, no. 3, pp. 235-240, 1987.

[7] R. Jack Dallman, W. J. Galyean, and K. C. Wagner, "Containment venting as an accident management strategy for BWRS with Mark I containments," Nuclear Engineering and Design, vol. 121, no. 3, pp. 421-429, 1990.

[8] D. L. Kelly, "Overview of containment venting as an accident mitigation strategy in US light water reactors," Nuclear Engineering and Design, vol. 131, no. 2, pp. 253-261, 1991.

[9] F. Gazzillo and W. E. Kastenberg, "Risk reduction by filtered venting in PWR large dry-containments," Nuclear Engineering and Design, vol. 77, no. 1, pp. 69-85, 1984.

[10] M. Gonzales-Cuesta, D. Okrent, and W. E. Kastenberg, "A study of risk reduction for some mitigation features for PWRs," Nuclear Engineering and Design, vol. 75, no. 1, pp. 13-22, 1983.

[11] R. Schechtman and C. D. Heising, "Risk assessment of the beneficial impact of a filtered venting containment system in a PWR with large, dry containment," Annals of Nuclear Energy, vol. 23, no. 8, pp. 641-661, 1996.

[12] G. Huang and L. Fang, "Feasibility research of containment venting for CANDU 6," Nuclear Engineering and Design, vol. 268, pp. 113-120, 2014.

[13] K. Yuan, D. Q. Guob, L. L. Tong, and X. W. Cao, "Evaluation of containment venting strategy via VFS path for advanced passive PWR NPP," Progress in Nuclear Energy, vol. 73, pp. 102-106, 2014.

[14] EPRI, "MAAP4-Modular Accident Analysis Program for LWR Power Plants," 1994.

[15] K. Vierow, Y. Liao, J. Johnson, M. Kenton, and R. Gauntt, "Severe accident analysis of a PWR station blackout with the MELCOR, MAAP4 and SCDAP/RELAP5 codes," Nuclear Engineering and Design, vol. 234, no. 1-3, pp. 129-145, 2004.

[16] EPRI, "Use of MAAP in support of Post-Fukushima Applications," 2013.

[17] PWROG, "Severe Accident Management Guideline," MUHP2310, 1994.

[18] KHNP, "Probabilistic Safety Assessment for OPR1000 Containment Performance Analysis," 2004.

[19] NRC, "Reactor Safety Study," WASH-1400, 1975. 


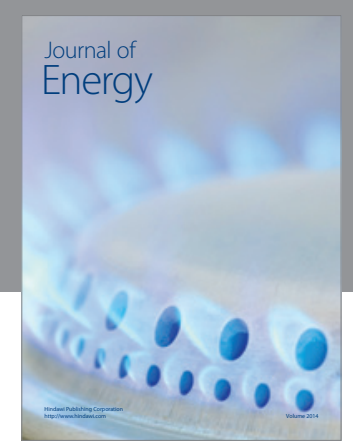

Journal of

Industrial Engineering
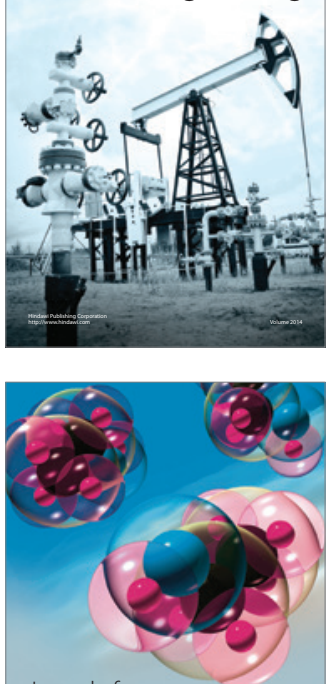

Fuels
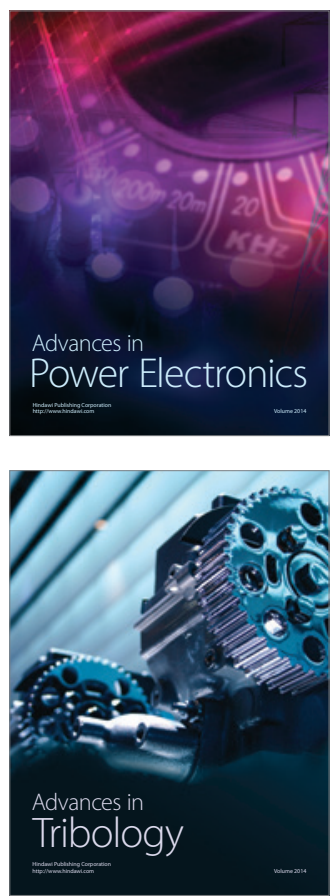

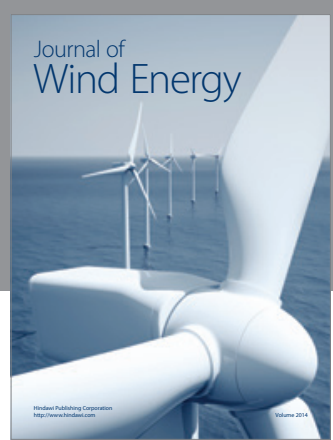

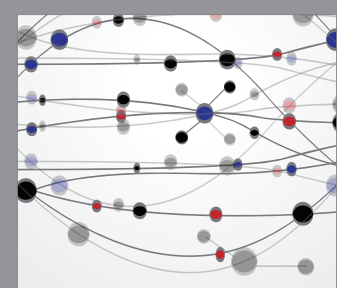

The Scientific World Journal

Submit your manuscripts at http://www.hindawi.com

Journal of

Structures
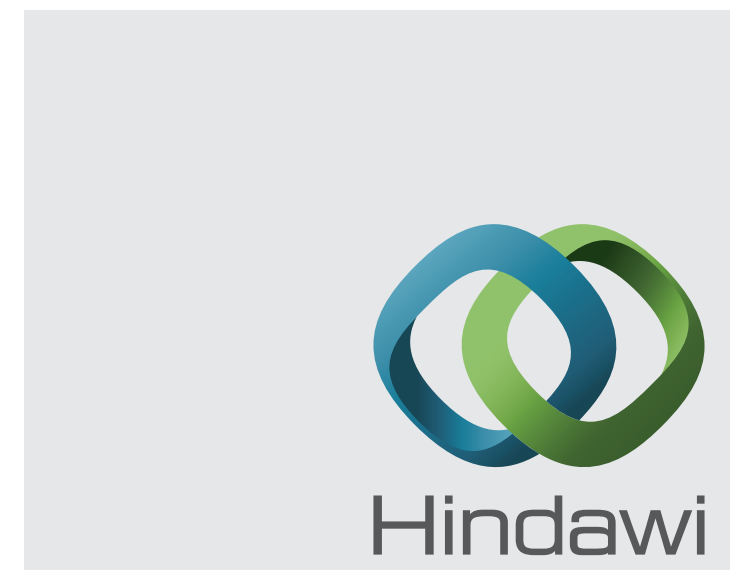

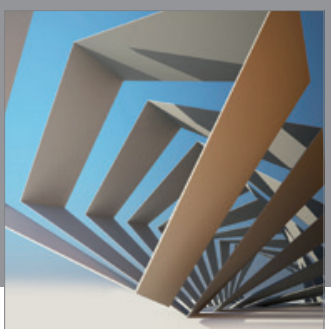

Rotating

Machinery
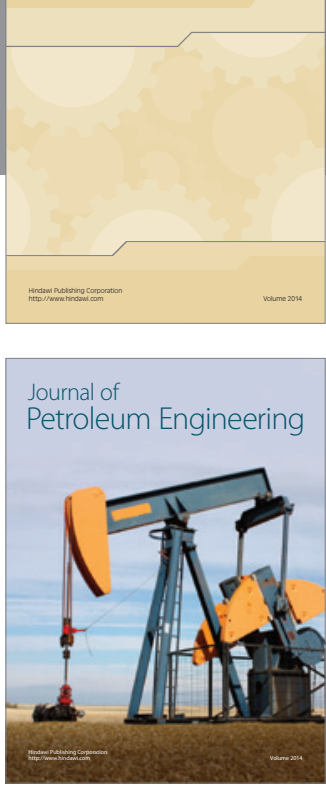

Journal of

Solar Energy
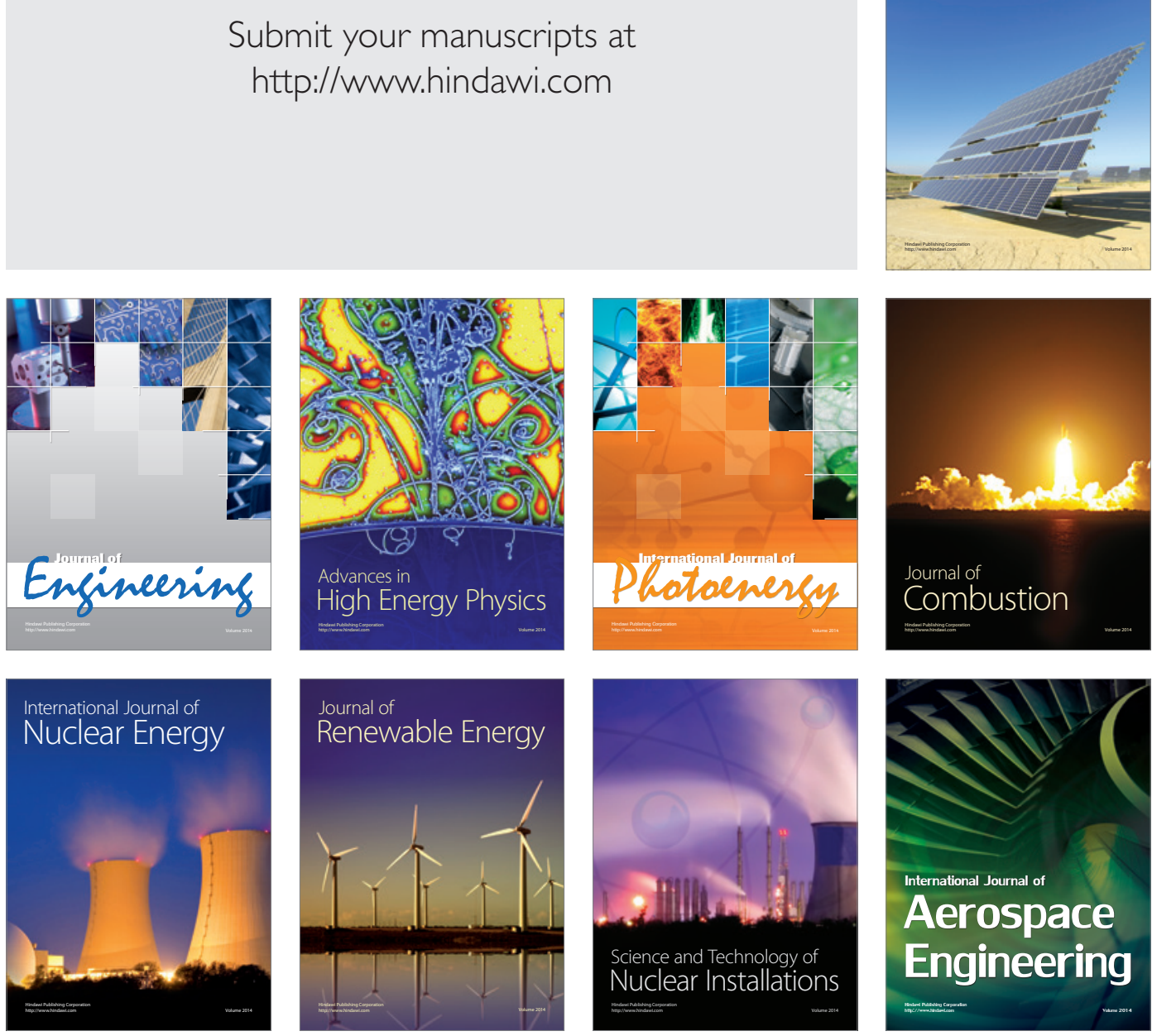